Fanum

Sociológico

\section{Forum Sociológico}

Série II

33 | 2018

Número 33

\title{
Cohen-Solal, A., \& Terroni, C. (Coords.) (2016). La valeur de l'art contemporain. Paris : PUF/La Vie des idées.
}

Joana Marques e Nadier Santos

\section{(2) OpenEdition \\ Journals}

Edição electrónica

URL: https://journals.openedition.org/sociologico/2477

DOI: $10.4000 /$ sociologico.2477

ISSN: 2182-7427

Editora

CICS.NOVA - Centro Interdisciplinar de Ciências Sociais da Universidade Nova de Lisboa

Edição impressa

Paginação: 57-59

ISSN: 0872-8380

Refêrencia eletrónica

Joana Marques e Nadier Santos, «Cohen-Solal, A., \& Terroni, C. (Coords.) (2016). La valeur de l'art

contemporain. Paris : PUF/La Vie des idées.», Forum Sociológico [Online], $33 \mid 2018$, posto online no dia

31 dezembro 2018, consultado o 31 março 2022. URL: http://journals.openedition.org/sociologico/

2477 ; DOI: https://doi.org/10.4000/sociologico.2477 


\title{
Cohen-Solal, A., \& Terroni, C. (Coords.) (2016). La valeur de l'art contemporain. Paris: PUF/La Vie des idées
}

\author{
Joana Marques \\ Laboratoire de sociologie, philosophie et anthropologie politiques (SOPHIAPOL), École Doctorale Economie, organisation, \\ société, Université Paris Nanterre - Paris X, France \\ Nadier Santos \\ Laboratoire d'études et de recherches sur les logiques contemporaines de la philosophie, École Doctorale Pratiques et \\ théories du sens, Université Paris 8 Vincennes - Saint-Denis, France
}

Esse livro propõe uma reflexão plural. Ele reúne contribuições de naturezas diversas (artigos, recensão e entrevista), mas também perspectivas diferentes: sociológica, histórica e econômica. Essa configuração permite assim esclarecer as diversas facetas da atribuição do valor da arte contemporânea em sua complexidade. Coordenado por Cristelle Terroni e apresentado por Annie Cohen-Solal, esse livro compõe-se de cinco textos curtos que trazem à luz as dimensões estéticas, políticas, sociais, culturais e econômicas desse fenômeno. Aproveitando a independência relativa dos capítulos, a presente recensão adota uma apresentação cuja ordem se diferencia da proposta no livro. Nós poderemos assim abordar de imediato a discussão central do livro, deixando para um momento subsequente as análises dos contextos específicos. Isso nos permitirá igualmente tratar conjuntamente alguns capítulos à luz do que eles possuem em comum.

Nesse sentido, para evidenciar os aspectos da avaliação da obra de arte contemporânea, podemos partir do segundo capítulo do livro: "Tudo que brilha não é ouro ${ }^{1 "}$. Neste, a economista Nathalie Moureau aponta um certo número de mudanças recentes no processo de atribuição do valor artístico. Outrora submetida às convenções acadêmicas, a avaliação da qualidade repousava sobre critérios bem definidos a partir dos quais era possível julgar as características intrínsecas de uma obra de arte. Atualmente, a qualidade desta última e sua legitimação decorem de uma série de interações entre diferentes atores dos mundos da arte que, contrariamente a uma conformidade às normas, avaliam a originalidade da proposta artística. São essas interações que tornam possível, por exemplo, a entrada de uma obra em uma coleção pública ou a obtenção do concurso de um crítico renomado. O conjunto desses atos, a sedimentação progressiva destes, garante a legitimidade de um trabalho artístico e acredita sua qualidade.
No entanto, o desenvolvimento do mercado da arte provocou uma disparidade entre valor artístico e valor de mercado. E a discussão sobre as consequências dessa disparidade atravessa todo o livro. A análise econômica vem então mostrar como aspectos relacionados ao consumo aí tomam parte. Assim, a busca por distinção social pela aquisição de bens que afirmam o poder e o prestígio, as estratégias mediáticas, a especulação ou as características da demanda são explicações potenciais ao fato que, sem nenhuma relação com seu reconhecimento artístico, um artista possa atingir um valor de mercado igual ao de um artista mais legitimado. Tais ocorrências são frequentemente decorrentes da implementação de estratégias mediáticas bem orquestradas ou de ações não relacionadas com o valor artístico de uma obra que levam os compradores a desembolsar um montante muito mais elevado que o aconselhado pelas instâncias de legitimação artística. A intensificação dessas práticas dá finalmente origem a bolhas especulativas.

Os capítulos um e cinco tratam, respectivamente, das cenas artísticas da França e do Japão. Esses dois países encontram dificuldades para lançar seus artistas no cenário internacional, notadamente em razão de sua inadequação à lógica global do mundo da arte contemporânea. Assim, em "Venturas e desventuras da França ante ao mercado da arte contemporânea2", a historiadora Annie Cohen-Solal apresenta a atitude francesa diante da arte contemporânea percorrendo as iniciativas adotadas para superar uma ampla estrutura estatal preocupada em preservar as tradições. Como explica a autora, durante as décadas de 1960 e 1970, a França era ainda reticente no tocante à arte contemporânea, o que atrasou sua afirmação na cena europeia. Mas o contraste mais marcante se estabelecia com os Estados Unidos. Com efeito, o sucesso da arte contemporânea estadunidense baseava-se em um modelo que sinalizava à França 
a necessidade de empreender um longo processo de transformação de suas estruturas institucionais, de seu regime fiscal, da dinâmica entre os diferentes atores e do papel das iniciativas privadas. Além disso, era preciso aproximar a produção artística contemporânea de um grande público até então indiferente a ela, à distância dos círculos elitistas e inacessíveis nos quais ela era difundida.

Embora a França tenha mudado positivamente sua imagem no cenário da arte contemporânea, um aspecto permanece inquietante: a fraca visibilidade internacional de seus artistas. Essa constatação põe, portanto, em causa a natureza e a eficácia de seu alinhamento em relação ao contexto global da arte contemporânea. Uma explicação é fornecida pelo viés econômico, pela análise das consequências do desenvolvimento acelerado do mercado e do papel crescente do poder financeiro ao longo das últimas duas décadas. Para Annie Cohen-Solal, diferentemente da China, da Grã-Bretanha ou da Alemanha, e a despeito de todas as suas transformações internas, a França não acompanhou as mutações de um mercado que, seguindo a lógica da economia global, põe em prática estratégias sofisticadas combinando marketing comercial, publicidade e difusão cultural. Reencontramos, portanto, aqui a mesma influência do mercado que faz confundir os valores de mercado e artísticos identificada por Nathalie Moureau.

O contexto francês é retomado no quarto capítulo a partir de uma entrevista com a historiadora Anne Martin-Fugier ${ }^{3}$. Depois de publicar duas coletâneas de entrevistas com galeristas e colecionadores franceses, essa autora decidiu interrogar uma dúzia de artistas para descobrir as razões de seu fraco reconhecimento internacional ${ }^{4}$. Se, abordando um contexto mais geral, Annie Cohen-Solal afirma que a França não constituiu uma rede capaz de projetar seus artistas na cena internacional da arte contemporânea pelo exercício de um poder de mercado, Anne Martin-Fugier chama a atenção para a complexidade das relações que esses artistas mantêm com os atores das redes e as condicionantes financeiras ou burocráticas que gravitam em torno de suas criações. As instituições culturais do sistema francês são os principais alvos dos artistas. Considerando o que se observa nos Estados Unidos, na Alemanha ou na Inglaterra, estes criticam tanto o funcionamento dessas instituições quanto seu fraco comprometimento com o êxito internacional de seus artistas. No entanto, eles não deixam de censurar igualmente os marchands, as galerias - seja por sua reticência no que respeita às parcerias internacionais ou por sua falta de sinergia - e os próprios artistas - por suas raras iniciativas de expatriação.

No último capítulo do livro, a socióloga Cléa Patin analisa a conjuntura japonesa em "Os artistas japoneses à prova da internacionalização $0^{5 "}$. A autora explica que o sucesso proporcionado pela lógica do mercado internacional a alguns artistas japoneses pôs em questão o percurso que, até os anos 2000, conduzia esses artistas ao reconhecimento fora do mercado japonês. De fato, se no Japão o acesso ao mercado internacional passava até então pela aquisição gradual de uma notoriedade nacional, o desenvolvimento de estratégias particularmente adaptadas ao mercado e postas em prática através da promoção internacional ofereceu aos artistas japoneses a oportunidade de considerar um sucesso a curto prazo. Contudo, e a despeito da adoção desse novo modelo pela maioria dos artistas em via de reconhecimento, essa prioridade dada à construção do valor de mercado das obras só se revelou eficaz de maneira excepcional.

Cléa Patin ressalta ainda aspectos culturais particulares que intensificam a dicotomia entre valor de mercado e apreensão estética da arte no Japão. Segundo a autora, no contexto cultural japonês a dimensão mercantil opõe-se de forma mais evidente a noções ligadas à emoção estética ou à expressão da interioridade do artista. Patin identifica no Japão uma "assimilação aprofundada" do mito romântico do artista maldito: o gênio disposto ao sacrifício e à abnegação em nome da paixão que o anima. Tudo isso favoreceu muito pouco a arte contemporânea no país. E para melhor entender a recepção da arte contemporânea no Japão podemos nos reportar ao terceiro capítulo do livro: "Como definir a arte contemporânea?6". Este capítulo é mais precisamente uma recensão de Le paradigme de l'art contemporain, livro de Nathalie Heinich?, realizada pela anglicista Cristelle Terroni. Segundo Heinich, no paradigma contemporâneo "a arte consiste em um jogo com as fronteiras do que é comumente considerado arte" (p. 49). Desse ponto de vista, a obra contemporânea se caracteriza por seu teor transgressivo, pelo questionamento das fronteiras da arte. Ela não está mais sujeita aos cânones da tradição ou ligada à expressão da interioridade do artista, sua abordagem é mais intelectual. Com efeito, sua apreensão passa por uma produção discursiva que visa tanto a dar conta dela quanto a valorizá-la, o que pode mesmo constituir uma espécie de "obstinação hermenêutica8". É, portanto, compreensível a desorientação do público após uma tal revogação das referências. Discutindo as propostas da arte contemporânea, Heinich chega mesmo a falar de um "efeito de surpresa, de interrogação, de perturbação perceptiva" (p. 55).

A exemplo dos artistas franceses, os artistas japoneses que obtiveram êxito através de suas estratégias de internacionalização criticam o fechamento do mercado nacional e a incapacidade das instituições japonesas de se alinharem às regras do mercado internacional. Eles defendem a busca por reconhecimento em mercados muito mais rentáveis no exterior, o que aliás garantir-Ihes-ia ao mesmo tempo o sucesso no mercado doméstico. 
Essa constatação é claramente atestada por uma galeria japonesa: «[Os marchands] confiam mais nas estimativas da Christie's e da Sotheby's que em seus próprios olhos" (p. 87). Assim, apesar das incertezas implicadas em um reconhecimento no exterior, numerosos são os artistas que preferem buscar seu lugar no mercado internacional em detrimento de uma carreira tradicional no Japão, onde o exercício é menos arriscado, mas o renome mais demorado a obter. Cléa Patin ainda acrescenta que o peso das experiências negativas desencadeadas pelo estouro da bolha especulativa no final dos anos 1980 continua a produzir efeitos sobre alguns atores do mercado japonês, preconizando prudência ante os movimentos do mercado e a natureza do reconhecimento de certos artistas nacionais. Para a autora, são finalmente essas incertezas e instabilidades que prejudicam a consolidação do mercado japonês e a inserção do conjunto de seus artistas no mercado internacional.

Apesar da presença opressiva das imposições do mercado de arte contemporânea, cuja incontornável lógica comercial é muitas vezes a causa das desilusões dos atores que não a levam devidamente em conta, o livro apresenta duas passagens nas quais a arte contemporânea é considerada de um ponto de vista diferente. Assim, na primeira passagem, Anne Martin-Fugier confessa que, no momento de entrevistar os colecionadores, sentiu "a necessidade de protestar contra o lugar-comum" que, desde o início dos anos 2000, considerava que a arte contemporânea encarnava "o triunfo do dinheiro e da especulação". A autora apresenta então uma perspectiva completamente diferente: "eu convivia apenas com apaixonados" (p. 60). Ela afirma que essa coletânea de entrevistas registra justamente testemunhos de colecionadores que, movidos por um desejo de novidade, atraídos pelo desconhecido, se endividam sistematicamente para comprar obras. A outra passagem encontra-se no texto de Annie Cohen-Solal. Primeiramente através das palavras do galerista Jean-Gabriel Mitterrand:

sempre há boas galerias [...] que fazem o trabalho com artistas realmente importantes, realmente essenciais no panorama artístico atual. Estes escapam à espiral da arte produzida para esse novo mercado dos hiper-ricos, e é reconfortante para o futuro dos melhores artistas. (p. 26)

Depois através do otimismo de uma outra referência a mundos da arte que coexistem, que por vezes se cruzam, mas que evoluem sobretudo em paralelo: "Apostemos que outras pistas serão em breve traçadas" (p. 27).

Por fim, esse trabalho coletivo abrange de maneira sucinta e bem estruturada diversos aspectos do valor artístico na atualidade. Em um contexto no qual o valor de mercado constitui um elemento determinante do mundo da arte contemporânea, essa abordagem pontuada por exemplos esclarecedores e que dá a palavra aos diferentes atores do mundo da arte agradará especialmente aos não especialistas interessados em compreender a complexidade da atribuição do valor artístico. Todavia, o livro convirá igualmente àqueles que já assimilaram os principais aspectos da arte contemporânea, graças nomeadamente à peculiaridade de algumas referências, como as coletadas nas entrevistas, ou ainda à especificidade de certas análises, como é o caso do capítulo consagrado à conjuntura japonesa. Um conjunto bem realizado.

\section{Notas}

1 "Tout ce qui brille n'est point or."

2 "Heurs et malheurs de la France face au marché de l'art contemporain."

3 "L'art contemporain à la française".

4 Martin-Fugier, A. (2010). Galeristes: Entretiens. Arles: Actes Sud.; Martin-Fugier, A. (2012). Collectionneurs: Entretiens. Arles: Actes Sud.; Martin-Fugier, A. (2014). Artistes: Entretiens. Arles: Actes Sud.

5 "Les artistes japonais à l'épreuve de l'internationalisation".

6 "Comment définir l'art contemporain?".

7 Heinich, N. (2014). Le paradigme de l'art contemporain. Structures d'une révolution artistique. Paris: Gallimard.

8 Nathalie Heinich, in: Terroni, C. (2016). Comment définir l'art contemporain?. In La valeur de l'art contemporain (p. 55). Paris: PUF/La Vie des idées.

Recebido a 23/04/2018. Aceite para publicação a 22/11/2018.

Joana Marques (joanakellymarques@yahoo.fr). Laboratoire de sociologie, philosophie et anthropologie politiques (SOPHIAPOL), École Doctorale Economie, organisation, société, Université Paris Nanterre Paris X, France. Université Paris Nanterre, École doctorale EOS Bât. René Rémond, 3è étage bureau 301A 200 avenue de la République 92001 Nanterre, France.

Nadier Santos (nadiers @yahoo.com.br). Laboratoire d'études et de recherches sur les logiques contemporaines de la philosophie, École Doctorale Pratiques et théories du sens, Université Paris 8 Vincennes - Saint-Denis, France. Université Paris 8, 2 rue de la Liberté, 93526 Saint-Denis Cedex, Bâtiment C - Salle C103, France. 